\title{
Validation of the Insomnia Severity Index on Patients Recovering from High Impact Car Accidents
}

\author{
Zack Z. Cernovsky, Larry C. Litman, and Vitalina Nosonova
}

\section{ABSTRACT}

Background: The Insomnia Severity Index (ISI) is widely used in clinical assessments of insomnia in patients injured in high impact motor vehicle accidents (MVAs). This study examines the criterion and convergent validity of ISI on this clinical population.

Method: De-identified archival data were available on 112 post-MVA patients (37 men, 75 women, mean age 38.8 years, $S D=13.1$ ). They completed the ISI as well as the Brief Pain Inventory, the Rivermead Postconcussion Symptoms Questionnaire, the Subjective Neuropsychological Symptoms Scale (SNPSS), Items 10 to 12 of the Whiplash Disability Questionnaire (ratings of depression, anger, and of anxiety), Whetstone Vehicle Anxiety Questionnaire, Driving Anxiety Questionnaire (DAQ), Steiner's Automobile Anxiety Inventory, and some of them also completed the PTSD Checklist for DSM-5 (PCL-5).

The ISI responses were also available from a community sample of 21 controls (10 men, 11 women, mean age of 39.2 years, $S D=18.5$ ).

Results: The mean ISI total score of post-MVA patients (23.6, $\mathrm{SD}=13.1)$ was significantly higher than the one of the controls $(6.0, \mathrm{SD}=5.4)$ and significant between groups differences in the same direction were also observed on all 7 individual ISI items: the magnitude of these underlying relationships ranged from Pearson point biserial $r$ of 0.68 to 87 . The ISI total score also significantly correlated with ratings of post-MVA pain, depression, generalized anxiety, scores on measures of the post-concussion and whiplash syndrome, PTSD, and on Whetstone's and DAQ measures of post-MVA driving anxiety.

Discussion and Conclusions: The results show an excellent level of criterion and convergent validity of ISI for clinical assessments of insomnia in postMVA patients.

Keywords: Insomnia, Insomnia Severity Index, Car Accidents, Pain, PostConcussion Syndrome, Whiplash Syndrome, PTSD.
Submitted : May 03, 2021

Published : May 24, 2021

ISSN: 2593-8339

DOI: $10.24018 /$ ejmed.2021.3.3.858

\section{Z. Z. Cernovsky*}

Department of Psychiatry, Western University, Ontario, Canada.

(e-mail: zcernovs ${ }^{\circledR}$ uwo.ca)

L. C. Litman

Department of Psychiatry, Western University, Ontario, Canada.

(e-mail: corvette033@hotmail.com) V. Nosonova

Medex Assessments, Inc., North

York, Ontario, Canada.

(e-mail:

vnosonova@ medexassessments.com)

\section{INTRODUCTION}

Sleep disorders are a frequent, yet often underdiagnosed and untreated medical condition that can be associated with adverse economic consequences due to impaired functioning in the workplace. A 2009 epidemiological study by Sivertsen's team [1] in Norway on 47,700 adults age 20 to 89 found insomnia symptoms in $13.5 \%$ of the population: the symptoms were more prevalent among women, older adults, and in individuals with less education. A frequent association with a mental health condition or pain was noted.

A 2013 study by Taylor's team [2] on 1,047 college students found that $9.5 \%$ of the sample met DSM-5 criteria for chronic insomnia.

Insomnia Severity Index (ISI) [3] is a widely used 7 item questionnaires for the assessment of insomnia. Each item of
ISI describes one of 7 frequently encountered aspects of disordered sleep: (1) difficulty falling asleep, (2) difficulty staying asleep, (3) problems waking up too early, i.e., unplanned, unwanted, undesirable awakenings too early, with an inability to resume sleep, (4) extent of subjective satisfaction with sleep, (5) if the patient's sleep problems are noticeable to others, (6) the patient's worries/distress about the sleep problems, (7) the extent to which the sleep problems interfere with daily functioning (daytime fatigue, mood, ability to function at work/daily chores, concentration, memory).

The validation of ISI was undertaken by Gagnon, Bélanger, Ivers, and Morin [4] in 2013 on a sample of 410 patients in primary care settings. The results indicated that ISI's internal consistency was excellent (Cronbach alpha was 0.92), and each individual item showed adequate discriminative capacity (rs ranging from 0.65 to 0.84 ). The 
cutoff score of $>14$ statistically demonstrated a sensitivity of $82.4 \%$, i.e., a relatively satisfactory ability of the ISI as a screening tool to detect cases of insomnia. The specificity of ISI was calculated as $82.1 \%$, i.e., as a satisfactory capacity of avoiding false positives: thus, only about $17.9 \%$ of cases would be classified as false positives. The ISI has been recently validated in different languages, e.g., in German [5], Portuguese [6], and Korean [7].

The standards of American Psychological Association for psychological tests [8] require that a test be validated on each particular clinical group of patients on which it is being used. The ISI is very convenient in psychological assessments of injured motorists, but no validation on this clinical population has been published. Patients injured in high impact motor vehicle accidents (MVAs) typically suffer from a polytraumatic symptom pattern that includes pain, insomnia, post-concussion syndrome, whiplash syndrome, PTSD, and anxiety [9]. The present study examines the convergent validity of ISI by calculating correlations to such variables clinically assumed to be associated with impaired sleep and common in injured motorists: pain, post-concussion and whiplash syndrome, post-accident depression and anxiety.

Clinical experience suggests that insomnia is more frequent in motorists recovering from their high impact accidents than in samples of normal population. In the present study, we examine the criterion validity of ISI by comparing ISI total scores and also scores on each of the 7 items of a community control sample with those of a sample of postMVA patients.

\section{METHOD}

As mentioned, this study compares responses to the Insomnia Severity Index (ISI) of post-MVA patients with those of a community control sample.

\section{A. Sample of Post-MVA patients}

De-identified archival data on medical assessments carried out from 2018 to 2020 were available on 112 post-MVA patients ( 37 men, 75 women). Their age ranged from 15 to 70 years, with the mean at $38.8(\mathrm{SD}=13.1)$. The time elapsed since the patients' MVAs ranged from 8 to 181 weeks, with the average at 51.0 weeks $(\mathrm{SD}=35.6)$, i.e., about a year. They all still experienced active post-accident symptoms that required medical investigations and therapy. For example, in the current climate of fiscal restraints, many would be referred for cervical or lumbosacral spinal MRI only after they complained of persistent pain in those areas for longer than a year or two.

The patients in this sample still experienced considerable pain (mean rating of $6.2, \mathrm{SD}=1.4$, on the "average pain" item of the Brief Pain Inventory [10]). Most of them experienced the post-concussion syndrome (scores ranging from 7 to 61 on the Rivermead scale [11], [12], with the mean of 46.1, $\mathrm{SD}=9.7)$. Their scores on the Subjective Neuropsychological Symptoms Scale (SNPSS) [13] ranged from 0 to 50 with the mean at 20.4 points $(\mathrm{SD}=10.7)$. The SNPSS measures postconcussive symptoms that are not listed in the Rivermead scale (e.g., tinnitus, impaired balance, syndrome of word finding difficulty) and also symptoms of the cervical and lumbosacral whiplash [14] (e.g., tingling, numbness, reduced feeling in the limbs, reduced muscular control over the limbs).

Available were also the patients' ratings on Items 10 to 12 of the Whiplash Disability Questionnaire [15], that is, ratings of depression, anger, and of anxiety via scales ranging from 0 ("not at all") to 10 ("always"). Their self-ratings of depression ranged from 4 to 10 points, with the mean at 8.3 $(\mathrm{SD}=1.7)$. Those of anger ranged from 3 to 10 , with the mean at 8.5 points $(\mathrm{SD}=1.4)$. Those of anxiety ranged from 2 to 10 , with the mean at 8.8 points $(\mathrm{SD}=1.5)$.

1Scores on the PTSD Checklist for DSM-5 (PCL-5) [16] were available for only a subsample $(\mathrm{N}=39)$ of these patients and ranged from 0 to 79 points with the mean of 56.2 $(\mathrm{SD}=15.7)$.

Most patients developed driving anxiety after their MVA. Their scores ranged from 24 to 92 (mean=65.7, $\mathrm{SD}=16.8$ ) on the Whetstone Vehicle Anxiety Questionnaire [17], from 40 to 121 (mean=92.3, $\mathrm{SD}=21.4$ ) on the Driving Anxiety Questionnaire (DAQ) [17], and from 8 to 18 (mean=15.1, $\mathrm{SD}=2.2$ ) on Steiner's Automobile Anxiety Inventory [18].

In their vehicular accident, 78 were the drivers, 18 were passengers, one drove a motorcycle, and 15 were pedestrians.

\section{B. Sample of Controls}

The ISI responses were also available from a community sample of 21 controls ( 10 men, 11 women). Their age ranged from 22 to 79 years, with the mean at $39.2(\mathrm{SD}=18.5)$.

These 21 controls did not differ significantly from the 112 post-MVA patients with respect to age (t-test, $\mathrm{p}>.05)$ and with respect to the proportions of men versus women $\left(\mathrm{x}^{2}\right.$-test, $\mathrm{p}>0.05)$.

\section{Estimates of the Usual Number of Hours of Sleep per Day}

The controls and the majority of the patients provided their estimates of how many hours of sleep per day they usually have obtained in the last 2 weeks. Furthermore, the postMVA patients also provided an estimate of hours of sleep per day they used to obtain prior to their MVA.

\section{RESULTS AND DISCUSSION}

As explained, this study examines the criterion and convergent validity of the Insomnia Severity Index (ISI) [3]. Each of the 7 items of ISI is scored on a scale from 0 to 4 , according to the intensity of the particular sleep problem.

For the first 3 items (Difficulty falling asleep, Difficulty staying asleep, and Problems waking up too early), the coding is as follows: $0=$ none, $1=$ mild, $2=$ moderate, $3=$ severe, 4=very severe.

For Item 4 (How satisfied/dissatisfied are you with your current sleep pattern), the coding is $0=$ very satisfied, $1=$ satisfied, $2=$ moderately satisfied, $3=$ dissatisfied, $4=$ very dissatisfied.

For Item 5 (How noticeable to others do you think your sleep problem is in terms of impairing the quality of your life?), $0=$ not at all noticeable, 1=a little, 2=somewhat, $3=$ much, $4=$ very much noticeable.

For Item 6 (How worried/distressed are you about your current sleep problem?), $0=$ not at all worried, $1=\mathrm{a}$ little, 2=somewhat, $3=$ much, $4=$ very much worried. 
For Item 7 (Sleep problem interferes with your daily functioning), the coding is $0=$ not at all interfering, $1=\mathrm{a}$ little, $2=$ somewhat, $3=$ much, $4=$ very much interfering [3].

\section{A. Criterion Validity of Insomnia Severity Index and of Its 7 Items}

The criterion validity of questionnaires such as ISI can be defined as the extent to which they indeed do what they are intended to do. Thus, the scores on the ISI and on its individual items should adequately differentiate patients with impaired sleep from a control group in which, on the average, more normal sleep patterns are expected.

From a clinical perspective, it appears that the patients would score higher on the ISI than controls because all ISI items seem to have satisfactory content validity: they all describe some aspect of sleep quality. However, statisticians would underscore the need to calculate the data to determine if the ISI and all its items indeed have a satisfactory criterion validity.

The mean ISI total score and mean scores on its individual items are listed in Table I as well as Pearson point biserial coefficients [19] indicating the size of the difference between our 2 groups. All of these correlations are significant and are uniformly high $(r>0.60)$, indicating high levels of criterion validity.

TABLE I: MEAN SCORES AND SDS ON ISI AND ON ITS 7 ITEMS OF POSTMVA PATIENTS AND OF CONTROLS

\begin{tabular}{lccc}
\hline & \multicolumn{2}{c}{ Means (SDs): } & \\
\cline { 2 - 3 } & $\begin{array}{c}\text { Post-MVA } \\
\text { patients } \\
\mathrm{N}=112\end{array}$ & $\begin{array}{c}\text { Controls } \\
\mathrm{N}=21\end{array}$ & $\begin{array}{c}\text { Point } \\
\text { biserial r }\end{array}$ \\
\cline { 1 - 2 } ISI total score & $23.6(13.1)$ & $6.0(5.4)$ & 0.86 \\
Item 1: falling asleep & $3.1(0.9)$ & $0.9(0.9)$ & 0.68 \\
Item 2: staying asleep & $3.1(0.8)$ & $0.8(1.1)$ & 0.72 \\
Item 3: early awakenings & $3.1(1.0)$ & $0.9(0.8)$ & 0.68 \\
Item 4: overall sleep satisfaction & $3.7(0.5)$ & $1.5(1.2)$ & 0.79 \\
Item 5: How noticeable to others? & $3.4(0.8)$ & $0.7(1.0)$ & 0.80 \\
Item 6: Worried/distressed about & $3.4(0.6)$ & $0.7(0.9)$ & 0.85 \\
sleep & $3.6(0.6)$ & $0.7(0.9)$ & 0.87 \\
Item 7: Interference with daily & & & \\
functioning & & & \\
\hline Legend: All correlations listed in Table I are significant at p<0.001, & -tailed
\end{tabular}

According to Morin et al. [3] the total scores of ISI can be interpreted by the following 4 categories:

No clinically significant insomnia: 0 to 7 ;

Subthreshold insomnia: 8 to 14 ;

Clinical insomnia, moderate: 15 to 21 ;

Clinical insomnia, severe: 22 to 28.

The proportions of our post-MVA patients and of controls in each of these categories are listed in Table II.

TABLE II: POST-MVA PATIENTS VERSUS CONTROLS IN ISI'S CLINICAL

\begin{tabular}{ccc}
\multicolumn{3}{c}{ CATEGORIES } \\
\hline & \multicolumn{2}{c}{ Proportions of persons } \\
\cline { 2 - 3 } Clinical category: & $\begin{array}{c}\text { Post-MVA } \\
\text { patients }\end{array}$ & $\begin{array}{c}\text { Control group } \\
\mathrm{N}=21\end{array}$ \\
& $\mathrm{~N}=112$ & \\
\hline No clinically significant insomnia: & $0 \%$ & $71.4 \%$ \\
Subthreshold insomnia: & $0 \%$ & $23.9 \%$ \\
Clinical insomnia, moderate: & $31.2 \%$ & $4.8 \%$ \\
Clinical insomnia, severe: & $68.8 \%$ & $0 \%$ \\
\hline
\end{tabular}

The underlying Spearman correlation is highly significant and inverse (rho=-0.70, $\mathrm{p}<0.001)$.

The results in Table I and Table II provide a strong statistical support in favor of the criterion validity of ISI.

\section{B. Convergent Validity of ISI}

Convergent validity (also referred to as concurrent validity) is the extent to which the scale correlates with variables to which it is theoretically expected to be related. Briefly, the ISI scores should correlate positively with psychological factors that interfere with normal sleep patterns, i.e., variables such as persistent pain, depression, and subjective symptoms within the post-concussion and whiplash spectrum. Variables such as generalized anxiety and high levels of driving anxiety can also have an adverse impact on sleep quality.

The data of post-MVA patients included the ratings of the worst, least, and average pain on items of the Brief Pain Inventory, ratings of depression, anger, and generalized anxiety on Items 10 to 12 of the Whiplash Disability Questionnaire, scores on the Rivermead Post-Concussion Symptom Questionnaire, Subjective Neuropsychological Symptoms Scale, the PTSD Checklist for DSM5 (PCL-5), and on 3 questionnaires for assessment of post-accident driving anxiety. The correlations of ISI total scores to these variables are listed in Table III.

\begin{tabular}{lcc}
\multicolumn{2}{l}{ TABLE III: CORRELATIONS OF ISI TO VARIOUS CLINICAL MEASURES } \\
\hline & $\begin{array}{c}\text { Pearson } \\
\text { Correlations }\end{array}$ & $\begin{array}{c}\text { Significance } \\
\text { values } \\
\text { (2-tailed) }\end{array}$ \\
\hline $\begin{array}{l}\text { Ratings on Items 3 to 5 of the Brief Pain } \\
\text { Inventory [10]: }\end{array}$ & \\
$\begin{array}{l}\text { Worst pain, N=112 } \\
\text { Least pain, N=112, }\end{array}$ & 0.42 & $\mathrm{p}<0.001$ \\
Average pain, N=111 & 0.29 & $\mathrm{p}=0.002$ \\
$\begin{array}{l}\text { Rivermead Post-Concussion Symptoms } \\
\text { Questionnaire [11], [12], N=106 }\end{array}$ & 0.44 & $\mathrm{p}<0.001$ \\
$\begin{array}{l}\text { Subjective Neuropsychological } \\
\text { Symptoms scale (SNPSS) [13], N=111 }\end{array}$ & 0.62 & $\mathrm{p}<0.001$ \\
$\begin{array}{l}\text { Ratings on Items 10 to 12 on the } \\
\text { Whiplash Disability Questionnaire [15] }\end{array}$ & 0.40 & $\mathrm{p}<0.001$ \\
$\begin{array}{l}\text { Depression, N=112 } \\
\text { Anger, 112 }\end{array}$ & & \\
$\begin{array}{l}\text { Generalized Anxiety, N=112 } \\
\text { PTSD Checklist for DSM-5 }\end{array}$ & 0.45 & $\mathrm{p}<0.001$ \\
(PCL-5) [16], N=39 & 0.41 & $\mathrm{p}<0.001$ \\
Whetstone Vehicle Anxiety & 0.40 & $\mathrm{p}<0.001$ \\
Questionnaire [17], N=86 & 0.51 & $\mathrm{p}=0.001$ \\
$\begin{array}{l}\text { Driving Anxiety Questionnaire (DAQ) } \\
\text { [17], N=90 }\end{array}$ & & $\mathrm{p}<0.001$ \\
$\begin{array}{l}\text { Steiner's Automobile Anxiety Inventory } \\
\text { [18], N=74 }\end{array}$ & 0.43 & $\mathrm{p}<0.001$ \\
\hline
\end{tabular}

Legend: Since the Item 5 of Rivermead also measures sleep impairment, we have calculated the correlation of ISI only to a revised total Rivermead score from which the Item 5 (sleep impairment) was deducted, to avoid an undue inflation of the correlation coefficient.

All correlations in Table III are significant at $\mathrm{p}<0.005$, 2-tailed, except the one involving Steiner's questionnaire which would not meet even the significance criterion of $<0.05$, 1 -tailed.

The correlations in Table III confirm the convergent validity of ISI: various clinical conditions potentially involved in triggering or enhancing sleep difficulties indeed correlate significantly with ISI. The only exception is the Steiner's Automobile Anxiety Inventory which has (compared to Whetstone's measure of driving anxiety or to DAQ) less items and scores its items only as dichotomies rather than assessing the intensity of each particular aspect of 
driving anxiety in a more detailed manner such as on a 4 point scale. However, the advantage of Steiner's questionnaire in the clinical work is its relative simplicity and suitability even for persons with low reading skills.

Very similar correlates of ISI to those reported here in Table III were also published in a previous study on another sample of 101 post-MVA patients in a 2018 study by Istasy, Cernovsky, Bureau, and Chiu [20]: the correlations of ISI were found with "depressive mood $(r=0.64)$ and also with the post-concussion syndrome even after the item dealing with impaired sleep was removed from the Rivermead $(r=0.66)$. The insomnia also correlated with measures of MVA related pain $(r=0.41)$, anxiety $(r=0.48)$, and anger $(r=0.39)$, postMVA neurological symptoms other than concussion $(r=0.36)$, and with diagnosis of PTSD $(r=0.50)$, but not with age and gender $(p>0.05)$ " [20]. Those past results also provide support for convergent validity of the ISI.

\section{Estimates of Hours of Sleep per Day}

Our 21 controls and also 100 of the post-MVA patients provided estimates of the numbers of hours of sleep per day they usually obtained in the last 2 weeks prior to their assessment. The average number of sleep hours of post-MVA patients (4.3 hours, $\mathrm{SD}=1.1)$ was significantly lower than of the controls ( 7.4 hours, $\mathrm{SD}=1.1)$ : the difference in sleep hours corresponds to the $r=0.74, p<0.001,2$-tailed.

The number of sleep hours correlated with ISI total scores and scores on each of the 7 individual items of ISI, as shown in Table IV. The almost uniformly high correlations of the number of sleep hours to ISI total scores and to each of individual ISI items provide an additional evidence for convergent validity of the ISI.

TABLE IV: CORRELATION OF HOURS OF SLEEP TO ISI TOTAL SCORE AND TO SCORES ON EACH OF ITS 7 ITEMS

\begin{tabular}{lc}
\multicolumn{2}{c}{ TO SCORES ON EACH OF ITS 7 ITEMS } \\
\hline \multicolumn{2}{c}{ Pearson r } \\
\hline ISI total score & 0.78 \\
Item 1: falling asleep & 0.59 \\
Item 2: staying asleep & 0.67 \\
Item 3: early awakenings & 0.70 \\
Item 4: overall sleep satisfaction & 0.72 \\
Item 5: How noticeable to others? & 0.73 \\
Item 6: Worried/distressed about sleep & 0.74 \\
Item 7: Interference with daily functioning & 0.73 \\
\hline
\end{tabular}

Legend: All correlations listed in Table I are significant at $\mathrm{p}<0.001,2$-tailed. The results are based on a combined sample of 100 post-MVA patients and of 21 controls.

The current number of sleep hours reported by post-MVA patients correlated at $\mathrm{p}<0.05,1$-tailed with their various measures of pain, post-concussion and whiplash symptoms, depression, and generalized anxiety, but not with the measures of PTSD and of driving anxiety, see Table V.

Except for the Rivermead scores, none of the other correlation coefficients involving the hours of sleep in Table $\mathrm{V}$ would reach the $\mathrm{p}<0.001,2$-tailed, unlike the correlations listed for ISI in Table III. The number of hours of sleep alone seems less adequate overall index of insomnia than the total score on the ISI.

Ninety-nine post-MVA patients also provided an estimate of hours of sleep per day for the time prior to their MVA. Their usual number of pre-MVA sleep hours (7.6, $\mathrm{SD}=1.0$ ) was significantly higher $(\mathrm{t}=28.9, \mathrm{df}=98, \mathrm{p}<0.001)$ than of their current post-MVA hours (4.3 hours, $\mathrm{SD}=1.1$ ).
The mean pre-MVA number of hours of our patients (7.6 hours, $\mathrm{SD}=1.0$ ) was not significantly different from the current mean number of sleep hours of our controls (7.4 hours, $\mathrm{SD}=1.1)$ : the underlying correlations is very low $(\mathrm{r}=0.07, \mathrm{p}=0.479,2$-tailed). If the patients' estimates of preMVA sleep time are correct, they seem similar to those of our controls who have not been injured in an MVA.

TABLE V: CORRELATIONS OF CURRENT NUMBER OF HOURS OF SLEEP TO OTHER CLINICAL MEASURES

\begin{tabular}{lcc}
\hline & $\begin{array}{c}\text { Pearson } \\
\text { rs }\end{array}$ & $\begin{array}{c}\text { Significance } \\
\text { (2-tailed) }\end{array}$ \\
\hline Ratings on Items 3 to 5 of the Brief Pain & & \\
Inventory [10]: & & \\
Worst pain, N=100 & 0.24 & $\mathrm{p}=0.016$ \\
Least pain, $N=100$ & 0.25 & $\mathrm{p}=0.014$ \\
Average pain, N=99 & 0.21 & $\mathrm{p}=0.039$ \\
Rivermead Post-Concussion Symptoms & 0.46 & $\mathrm{p}<0.001$ \\
Questionnaire [11], [12], N=94 & & \\
Subjective Neuropsychological Symptoms & 0.29 & $\mathrm{p}=0.003$ \\
scale (SNPSS) [13], N=99 & & \\
Ratings on Items 10 to 12 on the Whiplash & & \\
Disability Questionnaire [15] & 0.25 & $\mathrm{p}=0.011$ \\
Depression, N=100 & 0.23 & $\mathrm{p}=0.022$ \\
Anger, 100 & 0.17 & $\mathrm{p}=0.096$ \\
Generalized Anxiety, N=100 & 0.10 & $\mathrm{p}=0.584$ \\
PTSD Checklist for DSM-5 (PCL-5) [16], & & \\
N=34 & 0.16 & $\mathrm{p}=0.163$ \\
Whetstone Vehicle Anxiety Questionnaire & & \\
[17], N=78 & & $\mathrm{p}=0.191$ \\
Driving Anxiety Questionnaire [17], N=81 & 0.15 & $\mathrm{p}=0.576$ \\
Steiner's Automobile Anxiety Inventory & 0.07 & \\
[18], N=68 & & \\
\hline
\end{tabular}

Legend: Since Item 5 of Rivermead also measures sleep impairment, we have calculated the correlation of the number of hours of sleep only to a revised total Rivermead score from which the Item 5 (sleep impairment) was deducted, to avoid an undue inflation of the correlation coefficient.

\section{Correlations of ISI to Age, Gender, Number of Weeks since the MVA, and Number of Prior MVAs}

Total scores on ISI were not significantly correlated with age, number of weeks elapsed since the MVA, and number of prior MVAs: all these correlations failed to reach the significance criterion of $\mathrm{p}<0.05,2$-tailed). All patients in this sample still experienced active post-MVA symptoms requiring therapy.

The correlation of ISI to gender was statistically significant, with women obtaining slightly higher insomnia scores $(\mathrm{r}=0.19, \mathrm{p}=0.032,2$-tailed), however, the correlation coefficient is of low magnitude and would not be useful for adequate clinical predictions in individual cases.

\section{E. Internal Consistency and Item Total Correlations of ISI}

Cronbach alpha coefficient of internal consistency was calculated on pooled data of our 112 post-MVA patients and 21 controls: the coefficient was 0.96 , thus indicating an excellent internal consistency. The Cronbach alpha found in a 2013 study by Gagnon et al. [4] on primary care patients was similar (0.92).

In our study, the corrected item-total correlations ranged from 0.76 for Item 1 to 0.94 for Item 6. Deleting any particular one of the 7 items would result only in tiny changes of the alpha coefficient: the coefficient would still remain within the range from 0.94 to 0.96 . 


\section{CONCLUSIONS}

Using ISI clinical assessment criteria, only one of the controls was in the ISI category of clinically significant insomnia, with the score falling within the category of moderate insomnia. In contrast, all post-MVA patients met ISI criteria of insomnia: $31.2 \%$ were within the category of moderate and $68.8 \%$ in the category of severe insomnia.

The criterion validity of ISI in assessments of injured motorists is documented in our study by statistically significant differences in mean ISI total score and also in mean scores on all its individual items between post-MVA patients and the community control sample. Pearson point biserial correlation coefficients underlying these differences were all statistically significant and uniformly high $(r>0.60)$, indicating high levels of criterion validity.

Convergent validity of ISI is indicated by its statistically significant correlations to variables that may trigger or enhance insomnia: ratings of post-MVA pain, depression, generalized anxiety, scores on measures of the postconcussion and whiplash syndrome, PTSD, and on Whetstone's and DAQ measures of post-MVA driving anxiety. Briefly, the ISI can be considered as validated for patients injured in high impact MVAs.

\section{ACKNOWLEDGMENT}

The authors thank Abe Cernovsky, B. A., for his editorial assistance on this manuscript.

\section{REFERENCES}

[1] Sivertsen B, Krokstad S, Øverland S, Mykletund A. The epidemiology of insomnia: Associations with physical and mental health. The HUNT-2 study. Journal of Psychosomatic Research. 2009;67:109-116.

[2] Taylor DJ, Bramoweth AD, Grieser EA, Tatum JI, Roane BM. Epidemiology of insomnia in college students: relationship with mental health, quality of life, and substance use difficulties. Behavior Therapy. 2013;44(3):339-48. doi: 10.1016/j.beth.2012.12.001.

[3] Morin CM, Belleville G, Bélanger L, Ivers $\mathrm{H}$. The insomnia severity index: psychometric indicators to detect insomnia cases and evaluate treatment response. Sleep. 2011;34(5):601-608.

[4] Gagnon C, Bélanger L, Ivers H, Morin CM. Validation of the Insomnia Severity Index in primary care. Journal of the American Board of Family Medicine. 2013;26(6):701-10. doi: 10.3122/jabfm.2013.06.130064.

[5] Gerber M, Lang C, Lemola S, Colledge F, Kalak N, Holsboer-Trachsler E, Pühse U, Brand S.Validation of the German version of the insomnia severity index in adolescents, young adults and adult workers: results from three cross-sectional studies. BMC Psychiatry. 2016;16:174. (14 pages). doi: 10.1186/s12888-016-0876-8.

[6] Clemente V, Marques DR, Miller-Mendes M, Morin CM, Serra J, Gomes AA. The European Portuguese version of the insomnia severity index. Journal of Sleep Research. 2021;30(1):e13198. doi: $10.1111 /$ jsr.13198.

[7] Cho YW, Song ML, Morin CM. Validation of a Korean version of the insomnia severity index. Journal of Clinical Neurology. 2014;10(3):210-5. doi: 10.3988/jen.2014.10.3.210.

[8] American Educational Research Association, American Psychological Association, National Council on Measurement in Education. The Standards for Educational and Psychological Testing. Washington, DC.: AERA Publications, 2014.

[9] Gutierrez J, Nosonova V, Cernovsky Z, Fattahi M, \& Tenenbaum S. Gutierrez Questionnaire for Assessments of Patients after Car Accidents. Archives of Psychiatry and Behavioral Sciences. 2019;2(2):10-21. http://www.sryahwapublications.com/archives-ofpsychiatry-and-behavioral-sciences/pdf/v2-i2/3.pdf.

[10] Cleeland CS. The Brief Pain Inventory - User Guide. Houston, TX: The University of Texas - M. D. Anderson Cancer Center, 2009.
[11] King NS, Crawford S, Wenden FJ, Moss NEG, Wade DT. The Rivermead Post Concussion Symptoms Questionnaire: a measure of symptoms commonly experienced after head injury and its reliability. Journal of Neurology. 1995;242:587-592.

[12] Cernovsky ZZ, Mann SC, Velamoor V, Oyewumi LK, Diamond DM, Litman LC. Validation of the Rivermead Post-Concussion Symptoms Questionnaire (RPQ) on Patients Injured in High Impact Car Accidents. Archives of Psychiatry and Behavioral Sciences. 2021;4(1):14-22. doi.org/10.22259/2638-5201.0401003.

[13] Cernovsky ZZ, Litman LC, Mann SC, Oyewumi LK, Bureau Y, Mendonça JD, Diamond DM, and Raheb H. Validation of the Subjective Neuropsychological Symptoms Scale (SNPSS) in Injured Motorists. Archives of Psychiatry and Behavioral Sciences. 2021;4(1):6-13. http://www.sryahwapublications.com/archives-ofpsychiatry-and-behavioral-sciences/pdf/v4-i1/2.pdf.

[14] Cernovsky ZZ, Mann SC, Velamoor VR, and Oyewumi LK. The Need for Three Separate Parallel WAD Ratings of Whiplash Injuries to Cervical, Lumbosacral, and Thoracic Spine in Clinical Assessments of Injured Motorists. European Journal of Medical and Health Sciences. 2021;3(1):1-6. doi: 10.24018/ejmed.2021.3.1.699.

[15] Pinfold M, Niere KR, O'Leary EF, Hoving JL, Green S and Buchbinder R. Validity and internal consistency of a Whiplash-Specific disability measure. Spine. 2004;29(3):263-268.

[16] Weathers FW, Litz BT, Keane TM, Palmieri PA, Marx BP, \& Schnurr PP. The PTSD Checklist for DSM-5 (PCL-5). The National Center for PTSD, US Department of Veterans Affairs, Washington, DC, 2013. www.ptsd.va.gov.

[17] Whetstone JP, Cernovsky Z, Tenenbaum S, Poggi G, Sidhu A, Istasy M, Dreer M. Validation of James Whetstone's Measure of Amaxophobia. Archives of Psychiatry and Behavioral Sciences. 2020;3(1):23-33. http://www.sryahwapublications.com/archives-ofpsychiatry-and-behavioral-sciences/pdf/v3-i1/3.pdf.

[18] Cernovsky ZZ, Fattahi M, Litman LC, Tenenbaum S, Leung B, Nosonova V, Zhao C, and Dreer M. Validity of Steiner's Automobile Anxiety Inventory. European Journal of Medical and Health Sciences. 2021;3(1):56-61 doi: 10.24018/ejmed.2021.3.1.661.

[19] Cernovsky ZZ. A frequent misunderstanding associated with point biserial and phi coefficients. Psychological Reports. 2002;90(1):65-6. doi: 10.2466/pro.2002.90.1.65.

[20] Istasy P, Cernovsky Z, Bureau Y, Chiu S. Self-reported clinical correlates of insomnia. Archives of Psychiatry and Behavioral Sciences. 2018;1(2):23-25.

http://www.sryahwapublications.com/archives-of-psychiatry-andbehavioral-sciences/pdf/v1-i2/4.pdf.

Zack Z. Cernovsky is the professor of psychiatry in the medical school of Western University, London, Ontario, Canada. Dr. Cernovsky has published more than 200 scientific articles in the field of psychiatry and medical psychology, and also chapters in university textbooks.

Larry Craig Litman obtained his Ph.D. in clinical psychology from York University, Ontario, Canada. He has taught classes in statistics at that university. Dr. Litman is currently on faculty staff of the Department of Psychiatry, Schulich school of Medicine \& Dentistry, Western University, London, Ontario, Canada. He has published numerous empirical studies in clinical psychology and psychiatry.

Vitalina Nosonova is senior managerial staff of Medex Assessments, Inc. in the Greater Toronto Area, Canada and has co-authored psychological studies on patients injured in motor vehicle accidents. 